\title{
Sintese van Guerbet-tipe surfaktante en die bepaling van hulle toepassings
}

\author{
Outeurs: \\ Ettienne $\mathrm{H}$ Wiese \\ DP Otto \\ FTI Marx \\ HCM Vosloo \\ Affiliasie: \\ Navorsingsfokusarea \\ vir Chemiese Hulpbron- \\ verdeling, Katalise- en \\ Sintesenavorsingsgroep, \\ Noordwes-Universiteit, \\ Privaatsak X6001, \\ Potchefstroom, 2520, \\ Suid-Afrika \\ Korresponderende outeur: \\ DP Otto \\ E-pos: \\ Daniel.Otto@nwu.ac.za \\ Hoe om hierdie artikel aan \\ te haal: \\ Ettienne $\mathrm{H}$ Wiese, DP Otto, \\ FTI Marx, HCM Vosloo, \\ Sintese van Guerbet-tipe \\ surfaktante en die bepaling \\ van hulle toepassings, \\ Suid-Afrikaanse Tydskrif \\ vir Natuurwetenskap en \\ Tegnologie 39(1) (2020). \\ https://doi.org/10.36303/ \\ SATNT.2020.39.1.838 \\ Kopiereg: \\ (c) 2020. Authors. \\ Licensee: Die Suid- \\ Afrikaanse Akademie vir \\ Wetenskap en Kuns. \\ Hierdie werk is onder \\ die Creative Commons \\ Attribution License \\ gelisensieer.
}

Synthesis of Guerbet-type surfactants and the determination of their applications: This study entails the synthesis of ten different Guerbet-type surfactants and the determination of their applications. The surfactants are synthesised from $\alpha$-olefins, a by-product of the Fischer-Tropsch-process. The application of the surfactants is determined through the acquisition of their structural and physicochemical properties.

Die Suid-Afrikaanse petrochemiese industrie het sedert die 1950's voortdurend gegroei. Hierdie volgehoue groei het tot verskeie navorsingsgeleenthede in die velde van organiese en katalitiese chemie gelei. ' $n$ Voorbeeld van die navorsingsgeleenthede is om $\alpha$-olefiene, ' $n$ byproduk van die Fischer-Tropsch-proses, na meer bruikbare produkte om te skakel. Verskeie verbruikersgoedere naamlik smeermiddels, reinigingsmiddels, plastieke en verwante kunsstowwe asook surfaktante kan met omskakelingsreaksies gesintetiseer word. Sasol vervaardig hierdie $\alpha$-olefiene jaarliks in tonnemaatskaal. Dit word hoofsaaklik by diesel gevoeg. Dus bestaan daar'n geleentheid om die $\alpha$-olefiene na hoëwaardesurfaktante om te skakel. Alhoewel medium- en langketting-olefiene reeds as surfaktantvoorlopers beskikbaar is, bestaan daar ' $n$ leemte in die mark om kortketting-olefiene as surfaktantvoorlopers te benut.

Surfaktantnavorsing kan as die dryfveer vir die omskakeling van korterketting- $\alpha$-olefiene, met behulp van metatesereaksies na langerketting-olefiene, dien. Sodoende kan verdere surfaktantvoorlopers aan die mark gelewer word. Tydens die metatesereaksie word die normaalweg terminaal-onversadigde binding na die middel van die nuwe langerkettingolefien verplaas. Die reaksie lewer ook 'n bruikbare byproduk, naamlik etileengas. Etileengas word veral in polimerisasiereaksies aangewend om verskeie plastiekprodukte te vervaardig. Tot op hede het die Suid-Afrikaanse petrochemiese bedryf nie die volle toepassingspotensiaal van hierdie hulpbronne ontgin nie.

Surfaktante word tans in die Suid-Afrikaanse papiervervaardigingsbedryf aangewend om papierkwaliteit te beheer. Die surfaktante word aangewend om die poriegrootte tussen die papiervesels tydens die papiervervaardigingsproses te beheer. Die poriegrootte bepaal die mate waartoe vloeistowwe die papier kan indring. 'n Geskikte surfaktant het tot gevolg dat papiereienskappe vir spesifieke aanwendings aangepas kan word. Papiereienskappe wat deur die surfaktante verbeter kan word, is byvoorbeeld die verweerbaarheid van die papier, drukbaarheid, tekstuur, glans en oppervlakbindingsterkte. Ongelukkig word dié surfaktante ten duurste ingevoer omdat dit nie plaaslik vervaardig word nie.

Surfaktante word as brandstofbymiddels gebruik as gevolg van die gunstige funksies wat hulle verrig, soos byvoorbeeld die verlaging van oppervlakspanning, aanpakselverwydering, deeltjievormingvoorkoming, waterdispersie en oppervlakbeskermende laagvorming. Aanpaksels in petrolenjins kan verskeie uitlaat- en verrigtingsprobleme veroorsaak. Deur surfaktante by petrol te voeg, kan die hoeveelheid gevormde aanpaksels in inspuiters, verbrandingskamers en inlaatkleppe van petrolenjins verminder word. Verder is bevind dat die toevoeging van klein hoeveelhede water in koolwaterstofbrandstowwe, 'n positiewe uitwerking op die verbrandingsproses van petrolenjins het. Dié effek vind egter net plaas mits daar 'n emulsie uit water en petrol gevorm word. Emulsies met 5-10\% water kan die enjinwringkrag aansienlik verhoog. Die emulsies kan ook $\mathrm{NO}_{x}$ - en $\mathrm{CO}$-uitlating verlaag en $\mathrm{O}_{2}$ uitlating verhoog. Surfaktante is dus belangrik om die fisies-chemiese eienskappe van die emulsies te beheer.

Surfaktante is van die veelsydigste verbindings in die chemiese bedryf en het talle toepassingsmoontlikhede. Daarom is dit belangrik om die fisies-chemiese eienskappe van surfaktante te verstaan en die nodige kennis daaroor te ontwikkel.

Nota: 'n Seleksie van referaatopsommings: Studentesimposium in die Natuurwetenskappe, 31 Oktober - 1 November 2019 Universiteit van die Vrystaat. Reëlingskomitee: Prof Rudi Pretorius (Departement Geografie, Universiteit van Suid-Afrika); Dr Hertzog Bisset (Suid-Afrikaanse Kernenergie-korporasie; Dr Ernie Langner (Departement Chemie, Universiteit van die Vrystaat) en Dr Wynand Nel (Departement Rekenaarwetenskap en Informatika, Universiteit van die Vrystaat). 